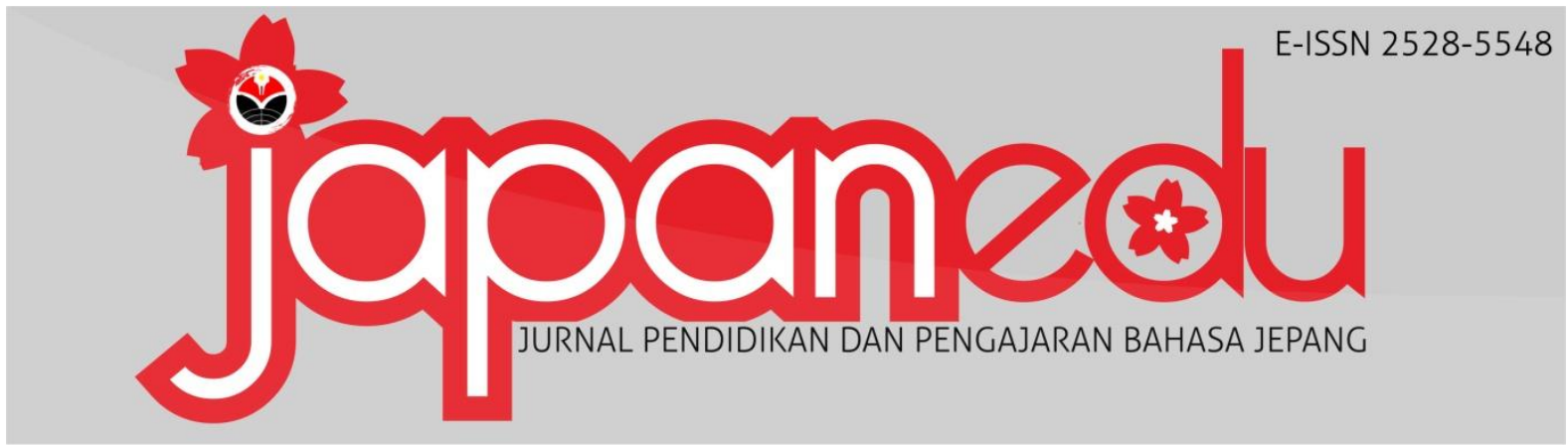

TEKNIK SHADOWING DALAM PEMBELAJARAN KA/WA

\title{
(Penelitian Eksperimen Terhadap Mahasiswa Tingkat II Tahun Akademik 2014/2015 Departemen Pendidikan Bahasa Jepang FPBS UPI)
}

\author{
Lanni Anggun Puspita, Melia Dewi Judiasri, Herniwati
}

Department of Japanese Language Education, Indonesia University of Education, Jl. Dr. Setiabudhi No. 229, Bandung 40154, Indonesia

E-mail: lanni.anggun@yahoo.com (Lanni),

Telp: +62-8131-2810-92

\begin{abstract}
Abstrak
Penelitian ini mencoba menerapkan teknik shadowing dalam pembelajaran kaiwa, terhadap mahasiswa tingkat II bahasa Jepang UPI. Bagi pembelajar bahasa Jepang, berbicara bahasa Jepang dengan lancar cukup menyulitkan karena perlu pembiasaan. Selain itu, saat berbicara perlu memperhatikan beberapa hal seperti, aksen, intonasi, panjang pendeknya pengucapan, juga pelafalan konsonan rangkap. Mengacu pada hal tersebut, teknik shadowing diterapkan agar mahasiswa terbiasa melatih mulutnya mengucapkan kata-kata dalam bahasa Jepang, sehingga dapat membantu meningkatkan kemampuan berbicara dan juga dapat menciptakan situasi kelas yang aktif. Tujuan penelitian ini adalah untuk memperoleh hasil tentang keefektivitasan dan tanggapan mahasiswa terhadap teknik shadowing untuk meningkatkan kemampuan berbicara dalam pembelajaran kaiwa. Kemudian, desain penelitian yang digunakan adalah pre-experimental design, yaitu dengan jenis yang dipilih one group pre-test - post-test design. Sampel penelitian berjumlah 10 orang mahasiswa tingkat II tahun akademik 2014/2015 dengan teknik nonprobability purposive sampling. Instrumen penelitian yang digunakan ialah tes lisan (oral) dan angket. Hasil analisis data yang diperoleh dari penelitian ini ialah nilai mean pre-test 39 dan nilai mean post-test 70. Sehingga terdapat peningkatan setelah diberikan treatment sebesar 31. Dari hasil tersebut didapat nilai $\mathrm{t}_{\text {hitung }} 11,2$ dengan $\mathrm{db}=9$. Maka, dapat disimpulkan bahwa $\mathrm{t}_{\text {tabel }} 2,26<\mathrm{t}_{\text {hitung }} 11,2$ untuk taraf signifikansi $5 \%$ dan nilai $\mathrm{t}_{\text {tabel }} 3,25<\mathrm{t}_{\text {hitung }} 11,2$ untuk taraf signifikansi $1 \%$. Kemudian hasil dari analisis angket dapat dikatakan bahwa respon mahasiswa positif dan teknik shadowing menarik juga menyenangkan diterapkan dalam pembelajaran kaiwa. Dengan demikian, teknik shadowing dirasa perlu diterapkan dalam pembelajaran kaiwa di kelas.
\end{abstract}


Kata kunci: teknik shadowing; kemampuan berbicara; pembelajaran kaiwa

\begin{abstract}
This study tried to apply shadowing techniques in kaiwa learning, toward the II degree Japanese students of FPBS UPI. For Japanese language learners, speaks Japanese fluently quite difficult because it needs to habituation. Additionally, when speaking need to consider several things like, accent, intonation, pronunciation short length, the pronunciation of consonant cluster. Referring to these, shadowing techniques applied to ensure that the students get used to train his mouth out the words in Japanese, so it can help improve the ability to speak and create a situation of active class. The purpose of this study is to obtain results about the effectiveness and student responses to the shadowing technique in enhancing the ability to speak in kaiwa learning. Then, the design of the study was used pre-experimental design, with the selected type one group pre-test - post-test design. These samples included 10 students II degree academic year 2014/2015 with nonprobability purposive sampling technique. The research instrument was used oral tests and questionnaires. The results of analysis of data obtained from this study are the mean value of pre-test 39 and mean value of post-test 70. So there was increased after being given treatment for 31 . From the results obtained with $t_{\text {count }} 11.2$ $\mathrm{db}=9$. Thus, it can be concluded that $\mathrm{t}_{\text {table }} 2.26<\mathrm{t}_{\text {count }} 11.2$ for a significance level of $5 \%$ and value $\mathrm{t}_{\text {table }} 3.25<\mathrm{t}_{\text {count }} 11.2$ to $1 \%$ significance level. Then the results of the analysis of the questionnaire can be said that the students had positive response and shadowing techniques are also fun exciting applied in kaiwa learning. Thus, it is necessary shadowing techniques applied in kaiwa learning in the class.
\end{abstract}

Keywords: shadowing techniques; speaking skills; kaiwa learning

\section{Pendahuluan}

Manusia yang menempuh berbagai fase dalam hidupnya tidak serta merta terampil dalam berbagai hal. Contohnya saja saat dalam fase bayi manusia tidak langsung pandai berbicara, namun berkat mendengar orang-orang di sekitarnya berkomunikasi, perlahan-lahan bayi akan menirukan suara yang dia dengar. Tahap mendengar dan menirukan suara ini ialah tahap awal manusia sehingga dapat berbicara. Dengan menggunakan bahasa sebagai alat komunikasi, manusia dituntut pula terampil dalam berbahasa. Tidak hanya bahasa ibu, bahasa asing sebagai bahasa kedua pun harus terampil dalam menggunakannya. Sehingga tidak heran pada jaman modern ini banyak sekali peneliti dan pembelajar bahasa asing. Salah satu diantaranya ialah pembelajar bahasa Jepang.

Sebagai pembelajar bahasa Jepang, tentu pembelajarnya harus memiliki kemampuan membaca, menulis, mendengarkan, termasuk juga berbicara. Seperti yang diungkapkan Harris (dalam Tarigan, 2008, hlm.1), Keterampilan berbahasa mempunyai empat komponen, yaitu: keterampilan menyimak, berbicara, membaca, dan menulis. Namun, bagi pembelajar bahasa Jepang, berbicara bahasa Jepang dengan lancar cukup menyulitkan karena perlu pembiasaan. Teori pembiasaan klasik dari Pavlov menganggap bahwa pembelajaran merupakan rangkaian panjang dari respon yang dibiasakan (Chaer, 2003, hlm.85). Selain itu, saat berbicara dalam bahasa Jepang pemakai harus memperhatikan beberapa hal seperti, aksen, intonasi, panjang pendeknya pengucapan, atau pelafalan konsonan rangkap.

Berdasarkan angket yang disebarkan pada tanggal 3 Desember 2014 kepada 10 orang mahasiswa tingkat II mengenai tanggapan mereka terhadap pembelajaran kaiwa, didapat bahwa enam orang dari mereka merasa puas dengan teknik yang digunakan saat ini. Namun, seluruhnya merasa masih tidak begitu lancar berbicara bahasa Jepang. Mengacu pada 
permasalahan tersebut, penulis mencoba menerapkan teknik shadowing untuk pembelajaran kaiwa agar mahasiswa melatih mulutnya untuk berbicara dalam bahasa Jepang, sehingga dapat membantu mahasiswa meningkatkan kemampuan berbicara (kaiwa) dan menciptakan situasi kelas yang aktif. Maka dari itu penulis mencoba mengambil judul penelitian untuk menyusun sebuah skripsi dengan judul "Teknik shadowing dalam Pembelajaran Kaiwa" (Penelitian Eksperimen Terhadap Mahasiswa Tingkat II Tahun Akademik 2014/2015 Departemen Pendidikan Bahasa Jepang FPBS UPI)

\section{Metode Penelitian}

Materi penelitian yang diberikan kepada partisipan pada penelitian ini adalah materi khusus untuk latihan shadowing level menengah yang diambil dari buku yang berjudul "Shadooingu Nihongo wo Hanasoo". Level menengah dipilih karena sampel penelitian ini merupakan mahasiswa siswa tingkat II yang berada pada level chuukyuu (menengah). Pada saat treatment, unit (bab) yang diambil ialah unit tiga dan empat yang setiap section membahas tema yang berbeda. Materi tersebut disajikan dalam $m p 3$, partisipan hanya mendengarkan mp3 dan berlatih shadowing tanpa melihat teks. (Teks materi terlampir) unitnya:

Berikut merupakan tema dari setiap

a. Dalam unit 3 berisi latihan percakapan yang lebih alami. Terdapat berbagai percakapan yang menggunakan verba intransitif/verba transitif, bentuk pasif, dan bentuk kausatif. Misalnya, te oku, suru koto ni narimashita, rashii desu, dll. Pada unit ini banyak cara merespon atau menjawab sesuatu yang memerlukan kehati-hatian;

b. Pada unit 4 berisi latihan untuk mencoba ungkapan yang menyatakan perasaan sendiri atau kondisi tertentu. Latihan tersebut dapat meningkatkan kemampuan berkomunikasi. Unit ini terdapat onomatope juga idiom, seperti wazawaza, maniau, kuchi wa wazawai no moto, kurikuri, dll.

Metode penelitian yang digunakan ialah pre-experimental design, yaitu dengan jenis yang dipilih one group pre-test - post-test design. Dalam penelitian ini dibandingkan hasil pretest dengan hasil setelah treatment yaitu post-test. Hasil pretest post test diolah

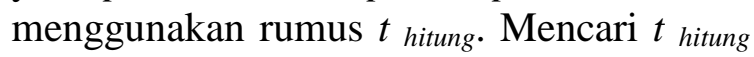
(uji $t$ ) untuk mengetahui pengaruh penerapan teknik shadowing. Di bawah ini tabel persiapan perhitungannya:

Berikut rumus uji t-hitung:

$$
M_{X}=\frac{\sum X}{N} \quad M_{Y}=\frac{\sum Y}{N}
$$

\section{Keterangan}

$M_{d} \quad$ : Mean gain antara post test dan pretest

$\sum x^{2} d:$ Jumlah kuadrat deviasi

$N \quad$ : Banyaknya sampel

Langkah-langkah dari $\mathrm{t}_{\text {hitung }}$ di atas ialah (Arikunto, 2006, hlm. 306):

a. Mencari Mean kedua variabel

$t=\frac{M d}{\sqrt{\frac{\sum x^{2} d}{N(N-1)}}}$

b. Mencari Gain (d) antara pretest dan post test

$d=$ posttest - pretest

c. Mencari nilai kuadrat deviasi

$$
\sum x^{2} d=\sum d^{2}-\frac{\left(\sum d\right)^{2}}{N}
$$

Sedangkan hasil data angket diolah menggunakan rumus sebagai berikut:

Keterangan:

$100 \%=$ Persentase frekuensi setiap jawaban responden 
$\mathrm{f}=$ Frekuensi setiap jawaban responden

$$
\begin{array}{ll}
\mathrm{n} & =\text { Jumlah responden } \\
\mathrm{P} & =\text { Presentasi jawaban }
\end{array}
$$

\section{Hasil Penelitian}

Mencari nilai $t_{\text {hitung }}$

$$
\begin{aligned}
& t_{0}=\frac{M d}{\sqrt{\frac{\sum x d^{2}}{N(N-1)}}} \\
& =\frac{31}{\sqrt{\frac{690}{10(10-1)}}} \\
& =\frac{31}{\sqrt{\frac{690}{10(9)}}} \\
& =\frac{31}{\sqrt{\frac{690}{90}}} \\
& =\frac{31}{\sqrt{7,67}} \\
& =\frac{31}{2,77} \\
& =11,2
\end{aligned}
$$

Dari hasil nilai $t_{\text {hitung }}$ dengan nilai $\mathrm{db}=$ 10-1 ialah 9, dapat diketahui bahwa nilai taraf signifikansi 5\% dari 11,2 ialah 2,26 dan nilai taraf signifikansi $1 \%$ dari 11,2 ialah 3,25 yang keduanya sama-sama lebih kecil dari nilai $t_{\text {hitung. }}$. Dengan $t_{\text {hitung }}$ lebih besar dari $t_{\text {tabel }}$ dapat disimpulkan bahwa mean kedua variabel memiliki perbedaan yang signifikan.

Dengan demikian pembuktian hipotesis kerja dan hipotesis nol ialah sebagai berikut:

- $\mathrm{H}_{\mathrm{o}}: \mu_{1} \geq \mu_{2}$ berarti hasil pretest lebih besar atau sama dengan hasil post test setelah treatment menggunakan teknik shadowing.

Hipotesis nol ditolak karena nilai $t_{\text {tabel }} 2,26$ $<t_{\text {hitung }} 11,2$ untuk taraf signifikansi 5\% dan nilai $t_{\text {tabel }} 3,25<t_{\text {hitung }} 11,2$ untuk taraf signifikansi $1 \%$.
- $\mathrm{H}_{\mathrm{k}}: \mu_{1}<\mu_{2}$ berarti hasil pretest lebih kecil dari hasil post test setelah treatment menggunakan teknik shadowing.

Hipotesis kerja diterima karena nilai $t_{\text {tabel }}$ $2,26<t_{\text {hitung }} 11,2$ untuk taraf signifikansi $5 \%$ dan nilai $t_{\text {tabel }} 3,25<t_{\text {hitung }} 11,2$ untuk taraf signifikansi $1 \%$.

Hal tersebut menunjukan bahwa terdapat perbedaan yang signifikan antara kemampuan berbicara partisipan dalam aspek kelancaran berbicara dan aspek pelafalan maupun intonasi bahasa Jepang sebelum dan sesudah menerapkan teknik shadowing. Berikut merupakan penjabaran hasil tes disertai teori yang mendukung:

> Sesuai dengan yang dikemukakan oleh Hiroshi dkk (2014, hlm. 8), dengan melaksanakan tahapan shadowing seperti, memilih materi yang tidak terlalu sulit diawal pertemuan, shadowing dalam hati, shadowing berbisik, kecepatan dalam berbicara perlahan-lahan meningkat. Partisipanpun terlatih menggerkan bibir dan mengucapkan ungkapan yang sulit;

Meskipun hanya delapan kali treatment, teknik shadowing yang bermanfaat menyeimbangkan input dan output (Hiroshi, dkk, 2013, hlm.10), terbukti menjadikan para partisipan mampu mengolah bahasa Jepang secara cepat dengan intonasi pengucapan yang semakin bagus; (lihat tabel 4.7)

Kemampuan berbicara para partisipan mengalami peningkatan, artinya kemampuan mengucapkan bunyi-bunyi artikulasi atau mengucapkan kata-katanya semakin baik. Hal tersebut karena digunakannya pula metode drill yang merupakan pengulangan berkali-kali agar asosiasi stimulus dan respon semakin kuat (Putra, 2013).

Kemudian, hasil dari analisis data non tes berupa angket menunjukan bahwa, teknik shadowing membantu meningkatkan kemampuan berbicara bahasa Jepang, yang dalam penelitian ini difokuskan pada aspek 
kelancaran berbicara, intonasi, dan pelafalan. Berlatih shadowing pun mempengaruhi spontasitasi partisipan dalam menjawab saat melakukan percakapan. Selain itu, perubahan yang dirasakan partisipan saat beberapa kali melakukan shadowing ialah pertama, intonasi dan pelafalan saat berbicara bahasa Jepang menjadi lebih baik. Hal tersebut dikarenakan partisipan cukup bisa mengikuti intonasi kata/kalimat dari $m p 3$ yang diputar. Kedua, menjadi lebih lancar berbicara bahasa Jepang. Ketiga, kemampuan chookai dan kaiwa meningkat, juga pembendaharaan kosakata pun bertambah.

\section{Kesimpulan}

Dengan dilaksanakannya penelitian ini didapatkan hasil bahwa kemampuan berbicara mahasiswa tingkat II tahun akademik 2014/2015 masih kurang. Hampir seluruh mahasiswa masih belum lancar berbicara bahasa Jepang, juga hanya sebagian kecil dari mahasiswa yang termasuk aktif berlatih berbicara. Namun, kemampuan mahsiswa tahun akademik 2014/2015 mengalami perubahan setelah diterapkannya teknik shadowing dalam pembelajaran kaiwa. Kemampuan berbicara mahasiswa tingkat II tahun akademik 2014/2015 (partisipan) dalam aspek kelancaran berbicara, pelafalan dan intonasi mengalami peningkatan berkat diterapkannya teknik shadowing. Teknik shadowing pun efektif digunakan untuk meningkatkan kemampuan berbicara (kelancaran, pelafalan dan intonasi) dalam pembelajaran kaiwa. Selain itu, tanggapan mahasiswa tingkat II (partisipan) terhadap penerapan teknik shadowing ini positif, mereka berpendapat bahwa teknik shadowing menarik diterapkan dalam pembelajaran kaiwa. Hal tersebut dapat membuat proses pembelajaran berjalan menyenangkan.

\section{Pernyataan}

Penulis mengucapkan terima kasih kepada Dra. Melia Dewi Judiasri, M.Hum.,M.Pd, Dr. Herniwati, M.Hum, Nashio Sensei atas dukungan, bimbingan, dan masukannya selama ini. Juga kepada para partisipan yang telah bersedia membantu dalam penelitian yang penulis laksanakan.

\section{Pustaka Rujukan}

[1] Chaer, Abdul. 2007. Kajian Bahasa (Struktur Internal, Pemakaian Dan Pembelajaran). Jakarta: Rineka Cipta.

$\begin{array}{lr} & 2003 . \\ \text { Psikolinguistik } & \text { kajian } \\ \text { Jakarta: Rineka Cipta. }\end{array}$

[2] Hiroshi, Saito, dkk. 2013. Shadooingu Nihongo wo Hanasoo . Sho Chuukyuuhen. Tokyo: Kuroshio.

2014.

Shadooingu Nihongo wo Hanasoo . Chuu Joukyuuhen. Tokyo: Kuroshio.

[3] Sutedi, Dedi. 2009. Penelitian Pendidikan Bahasa Jepang. Bandung: Humaniora.

2011. Penelitian Pendidikan Bahasa Jepang. Bandung: Humaniora.

Pengantar 2013. Hand Out Statistik. Modul Pendidikan bahasa Jepang UPI. Bandung: tidak diterbitkan.

[4] Tarigan, Henry G. 2008. Berbicara Sebagai Suatu Keterampilan Berbahasa. Bandung: Angkasa.

[5] Rohaeti, Teti. 2014. Pembelajaran Kooperatif Teknik Story Telling Terhadap Keterampilan Berbicara Bahasa Jepang (Penelitian Eksperimen Kuasi Terhadap Siswa 
Kelas XI IPA 2 SMA Pasundan 3

Bandung). Skripsi UPI. Bandung: tidak diterbitkan.

[6] Putra, Yhuto W. 2013. Metode Pembelajaran Drill. [online].

Tersedia:

http://yhutowputra.blogspot.com/20

13/06/metode-pembelajaran-drill-

a.html. (25 April 2015) 